\title{
COPD characteristics and socioeconomic burden in Hellenic correctional institutions
}

\author{
This article was published in the following Dove Press journal: \\ International Journal of COPD \\ 12 February 2016 \\ Number of times this article has been viewed
}

\section{Eleni G Bania' \\ Zoe Daniil' \\ Chrysa Hatzoglou' \\ Evangelos C Alexopoulos ${ }^{2}$ \\ Eirini Mitsiki ${ }^{3}$ \\ Konstantinos I \\ Gourgoulianis'}

'Respiratory Medicine Department, University of Thessaly Medical School, University Hospital of Larissa, Larissa,

${ }^{2}$ Faculty of Social Sciences, Hellenic Open University, Patras, ${ }^{3}$ Medical

Department, Novartis Hellas, Athens, Greece
Correspondence: Eleni G Bania University of Thessaly Medical School, Biopolis, Larissa 41500, Greece Tel +30695800 8644

Email bania.eleni@hotmail.com
Background: The high prevalence of smoking (80\%) in Greek correctional institutions is anticipated to result in high prevalence of COPD in such settings.

Aim: The aim of the Greek obstructive luNg disease epidemiOlogy and health economics Study In corrective institutionS (GNOSIS) is to determine the prevalence of smoking and COPD among inmates and to assess the health-related quality of life.

Methods: GNOSIS, a cross-sectional epidemiological study, was conducted between March 2011 and December 2011 in seven correctional institutions in Greece.

Results: A total of 552 participants, $91.3 \%$ male, median age of 43.0 years (interquartile range: $35-53$ ), were enrolled. COPD prevalence was $6.0 \%$ and was found to increase with age ( $18.6 \%$ among those $\geq 60$ years), length of prison stay, and length of sentence. Of the participants diagnosed with COPD, $36.4 \%$ were diagnosed with Global initiative for chronic Obstructive Lung Disease (GOLD) stage I and 51.5\% were diagnosed with stage II. Dyspnea severity was assessed as grades $0-1$ on the medical research council dyspnea scale for $88.3 \%$, while $31 \%$ reported $\geq 2$ COPD exacerbations in the past year. Seventy-nine percent of the total number of the participants were smokers, with a median smoking of 20.0 cigarettes per day, while $42.9 \%$ were assessed as having a strong addiction to nicotine. The median EuroQol visual analog scale score was 70.0 (interquartile range: $60.0-90.0$ ). Problems in the dimension of anxiety/depression were reported by $82.8 \%$.

Conclusion: The results of the study support the notion that the prevalence of COPD among inmates of Greek correctional institutions may increase in the following years. The findings underscore the importance of taking actions to limit COPD prevalence and its risk factors in the Greek correctional system.

Keywords: smoking, stress, correctional institutions, Greece, prevention, public health

\section{Background}

COPD is high socioeconomic burden and is a major cause of morbidity and mortality worldwide. According to the World Health Organization, 65 million people worldwide suffer from moderate-to-severe COPD, while in 2012, the disease was responsible for $5.6 \%$ of all deaths (3.1 million) that occurred globally. ${ }^{1,2}$ COPD is projected to be the third leading cause of mortality and the fifth cause of disability-adjusted life years lost worldwide by $2020{ }^{1,3}$

The prevalence of COPD in Greece is estimated to be $8.4 \%,{ }^{4}$ with underdiagnosis of the disease in primary care remaining a prominent concern., ${ }^{5,6}$ Tobacco smoking represents the major risk factor for COPD development and progression. ${ }^{1}$ In Greece, smoking prevalence has reached epidemic proportions. Among members of the European Union, Greece has one of the highest consumption rates of tobacco products, with an estimated average of 2,458 sticks per capita for 2010, equivalent to a total of 27.7 billion cigarettes 
for the overall Greek population. ${ }^{7}$ The 2009 report of the Ministry of Health and Social Solidarity, the 2010 report of the Hellenic Action Through Research Against Tobacco Project, and the 2011 report by the Greek Center for Disease Control (KEELPNO) estimate smoking prevalence among adults to be $38.2 \%, 41.0 \%$, and $33.5 \%$, respectively. ${ }^{7,8}$

Importantly, prevalence of smoking is especially high in Greek correctional institutions, reported to be $80 \%$ and $77.5 \%$ in studies conducted at the detention premises of Halkida ${ }^{9}$ and Volos, ${ }^{10}$ respectively. In addition, apart from smoking, several other factors underscore the importance of estimating the prevalence of COPD in the setting of the Greek correctional system. Specifically, data from the Greek Ministry of Justice suggest that the prison population of Greece will continue to grow and age given that in 2012 , nearly $59 \%$ of the inmates (excluding those in custody) had been sentenced to $>10$ years of imprisonment (a figure that includes life termers). ${ }^{11}$ Moreover, a report of the European Prison Observatory indicates that, in 2013, Greece had a prison density of $126 \%$, denoting that the country's prison system is overcrowded, ${ }^{12}$ a factor that may augment the prevalence of diseases. In fact, it has already been reported that communicable conditions such as hepatitis are highly prevalent among inmates; ${ }^{13,14}$ however, data on the prevalence of noninfectious conditions within the Greek correctional system are scarce.

Among published reports on the prevalence of chronic conditions conducted in prison settings, a study conducted in the Spanish prison population ranked COPD as the fifth most prevalent chronic condition with a rate of $2.2 \%$, trailing behind dyslipidemia, hypertension, diabetes, and asthma. ${ }^{15}$ Moreover, studies conducted in US prison populations indicate that the prevalence of certain chronic conditions in correctional institutions tends to be higher, or at least similar to that of the general population. ${ }^{16-19}$

In light of the aforementioned facts, and especially considering the high prevalence of smoking in the Greek population, the overcrowding, and anticipated population aging in the Greek correctional institutions, the poor indoor air quality that promotes secondhand tobacco exposure has been linked with lung diseases; the estimation of the prevalence of COPD in the prison system of Greece is warranted.

Furthermore, this study was designed to estimate the prevalence of smoking and to gain insights into the risk factors and the impact of COPD on the correctional health care system of Greece, aiming toward the early detection and secondary prevention of COPD in this vulnerable population.

The Greek obstructive luNg disease epidemiOlogy and health economics Study In corrective institutionS (GNOSIS) aimed at recording the clinical characteristics of the imprisoned population, the presence of COPD, its severity and management, and the burden of COPD in terms of symptoms, exacerbations, and hospitalizations.

\section{Methods}

\section{Study design and objectives}

COPD is a major cause of morbidity and disability worldwide and one of the leading causes of mortality in the USA and Europe.

In Greece, the smoking-related mortality reaches 19.3\%, and the prevalence of COPD is estimated to be $8.4 \%$ of the general population, with many of the patients being unaware of their disease.

A population in which the number of smokers is expected to be significantly high is the population of the correctional institution.

GNOSIS was a cross-sectional, epidemiological study, conducted between March 6, 2011 (start of data collection) and December 30, 2011 (end of data collection). The primary objective of the GNOSIS was to determine the prevalence of smoking and the prevalence of COPD among inmates of Greek correctional institutions. The study was completed in a single visit where all relevant information was recorded in the case report form specific for this study. A total of seven correctional institutions across six cities in Greece participated in the GNOSIS: the male and the female detention premises of Korydallos based in Attica and the detention premises of Halkida, Patras, Amfissa, Larissa, and Volos. The design of the study mirrored the real-life management of inmates and patients with COPD.

\section{Study population}

The study recruited inmates, according to the site-specific targets, who fulfilled all of the study eligibility criteria.

Inclusion criteria:

1. males and females $>30$ years irrespective of their smoking habit,

2. inmates in the Greek corrective institutions that have provided their written consent to participate in the GNOSIS study.

Exclusion criteria:

1. inmates that have not provided their written consent for participation in the GNOSIS study.

Eligibility criteria for participation in the GNOSIS were all inmates aged $>30$ years of both sexes, regardless of their current smoking status and smoking history. Participants voluntarily participated in this study and were selected by 
each investigator after evaluation, provided they fulfilled the eligibility criteria.

The study has run in six cities all over Greece: Athens, Halkida, Patra, Larissa, Amfissa, and Kassaveteia Volou.

Prisoners have been voluntarily included in the study in a single visit, and the data were collected over the period of March 2011 to December 2011.

Data were collected in a single study visit through physicians' assessment, physical examination, participants' interview, and completion of participant-reported outcomes (PROs). Data recorded included participants' demographic and anthropometric characteristics; COPD risk factors (eg, smoking history, length of prison stay, infections, and drug use); COPD comorbidities; sentence length; nicotine dependence level based on the Fagerström questionnaire; ${ }^{20}$ stress and its impact on the daily routine of inmates using the 14-item perceived stress scale (PSS-14); ${ }^{21,22}$ and healthrelated quality of life (HRQoL) using the generic three-level EuroQoL Group's five-dimension (EQ-5D-3L) instrument validated in the Greek language..$^{23,24}$ The Greek version of the PSS-14 was used for the assessment of the respondent's perception of stressful experiences over the past month. The scale contains seven negative and seven positive items; each rated on a five-point scale (from $0=$ never to $4=$ very often) rated on a scale of $0-4$. The 14 -item evaluates the ability to cope with perceived stressors and assesses the lack of control and negative emotions regarding events and situations that occurred over the previous month. The theoretical scale score ranges from 0 to 56 with higher values indicating greater perceived stress..$^{20,21}$

In addition, spirometery testing, oximetry, and vital sign assessment were performed during the single visit through spirometers, pulse oximeters, and manometers, respectively. Spirometry was used to evaluate the presence and degree of airflow limitation, following which the investigator reported whether the participant was in fact a patient suffering from COPD, according to the Global initiative for chronic Obstructive Lung Disease (GOLD) guidelines. ${ }^{3}$ Data collection was carried out through paper case record forms, while data processing, validation, and analysis were performed by an independent third party in compliance with the data protection principles and regulation.

The study was conducted under the auspices of the Hellenic Thoracic Society, and the initiative received the favorable opinion of the Hellenic Ministry of Justice, Health Scientists Council. The study was approved by the Scientific Committee of the University Hospital of Larissa. The study was conducted in accordance with ethical principles that have their origin in the Declaration of Helsinki and all applicable European Union and local laws and regulations that govern the conduct of such studies.

\section{Statistical methods}

Taking into account the cross-sectional, epidemiological study design and the fact that the objectives of the study did not aim at testing a specific statistical hypothesis, no formal calculation of the study sample size took place. No predefined accuracy or power assumption had been made due to the purely descriptive nature of the study.

Absolute and relative frequencies were used for the description of the qualitative characteristics of this study. The description of quantitative characteristics was based on the median and interquartile range ( $\mathrm{IQR}^{15}$ ). The estimation of the $95 \%$ confidence interval (CI) for the prevalence of COPD was based on the binomial distribution. ${ }^{16}$ Pearson's chi-squared test ${ }^{17}$ was used to assess the association between COPD and the various qualitative variables.

The association between scales was estimated using Spearman's rank correlation coefficient ${ }^{18}$ (Spearman's $\rho$ ). Locally weighted scatterplot smoothing (LOWESS) was applied in order to improve the graphical representation of the associations between the quantitative variables.

Multiple linear regression was used to model PSS-14. EQ-5D and the personal evaluation of the present medical condition were used as indicators of higher health level $(>80 \%)$. Logistic regression was applied to model higher health level. Variable selection in all multivariable models was based on backward elimination procedure, with a cutoff $P$-value of 0.1 . Site, age, and sex were included in all multivariate models irrespective of the significance level.

Taking into account the cross-sectional, epidemiological study design and the fact that the objectives of the study did not aim to prove or reject a predefined statistical hypothesis, no formal calculation of the study sample size took place.

The institutions included the male and the female detention premises of Korydallos based in Attica and the detention premises of Halkida, Patras, Amfissa, Larissa, and Volos. In the selected premises, all inmates were invited to participate. The study recruited a total of 552 inmates who fulfilled all of the study eligibility criteria and gave their written informed consent to participate. Eligibility criteria for participation in the GNOSIS were all inmates aged $>30$ years of both sexes, regardless of their current smoking status and smoking history. Participants were consecutively selected 
and were included in the study upon provision of their written informed consent.

Absolute and relative frequencies have been used for the description of the qualitative characteristics of this study. Quantitative characteristics are presented as median and IQR. The estimation of the 95\% CI for the prevalence of COPD was based on the binomial distribution. Pearson's chi-squared test was used to assess the association between COPD and the various qualitative variables.

Statistical comparisons of health/stress scales (PSS-14, EQ-5D-3L) between those suffering from COPD and COPDfree individuals were performed using the nonparametric Mann-Whitney $U$ test.

\section{Results}

\section{Participant characteristics}

A total of 552 eligible inmates were enrolled with a median age of 43.0 years (IQR: 35-53 years). The majority $(91.3 \%)$ was male and 79.2\% were Greek. More than half (54.6\%) had not completed senior high school education. Moreover, $48.0 \%$ of the participants had been sentenced to $<2$ years of imprisonment, $19.2 \%$ had been sentenced to 2-9.9 years of imprisonment, and the remaining $32.8 \%$ had been sentenced to $>10$ years of imprisonment. At the time of the study visit, for $46.7 \%$ of the participants, the length of stay had been $<2$ years. Participants' characteristics are presented in Table 1.

\section{Prevalence of smoking and associated factors}

The prevalence of smoking was found to be $79.0 \%$ (436/552). Of the participants, 36.3\% (200/552) had tried to quit smoking, while $40.4 \%$ (223/552) reported an increase in smoking since imprisonment. Of those completing the Fagerström questionnaire assessing nicotine dependence $(\mathrm{n}=550), 42.9 \%$ displayed a strong nicotine addiction, while $29.3 \%$ displayed a moderate nicotine addiction. Smokers reported a median of 20 cigarettes smoked per day (IQR: 15-40), the expense of which was covered mostly on their own (48.2\%) and also from parents $(22.7 \%)$ and/or others $(31.9 \%)$.

\section{Prevalence of COPD and patient characteristics}

COPD prevalence among inmates of Greek detention premises was estimated to reach 5.98\% (33/552; 95\% CI: 4.15-8.29). Slightly more than half of those diagnosed $(54.5 \%)$ were newly diagnosed. Among participants
Table I Participants' sociodemographic, anthropometric, and imprisonment characteristics

\begin{tabular}{|c|c|c|}
\hline$N=552$ & Median & $\begin{array}{l}\text { Interquartile } \\
\text { range }\end{array}$ \\
\hline Age (years) & 43.0 & $35.0-53.0$ \\
\hline Weight (kg) & 81.0 & $71.0-91.0$ \\
\hline Height (cm) & 175.0 & $170.0-180.0$ \\
\hline \multirow[t]{2}{*}{ BMI $\left(\mathrm{kg} / \mathrm{m}^{2}\right)$} & 26.6 & 23.9-29.3 \\
\hline & $\mathbf{n}$ & $\%$ \\
\hline \multicolumn{3}{|l|}{ Sex } \\
\hline Male/female & $504 / 48$ & $91.3 / 8.7$ \\
\hline \multicolumn{3}{|l|}{ Age group } \\
\hline 30 to $<40$ years & 216 & 39.1 \\
\hline$>40$ to $<50$ years & 156 & 28.3 \\
\hline$>50$ to $<60$ years & 121 & 21.9 \\
\hline $60+$ years & 59 & 10.7 \\
\hline \multicolumn{3}{|l|}{ Nationality } \\
\hline Greek/others & $437 / 115$ & $79.2 / 20.8$ \\
\hline \multicolumn{3}{|l|}{ Marital status } \\
\hline Married & 231 & 41.8 \\
\hline Single & 175 & 31.7 \\
\hline Divorced or separated & 129 & 23.4 \\
\hline Widowed & 17 & 3.1 \\
\hline \multicolumn{3}{|l|}{ Educational level } \\
\hline Illiterate & 22 & 4.0 \\
\hline Primary education & 134 & 24.3 \\
\hline Junior high school graduate & 145 & 26.3 \\
\hline Senior high school graduate & 153 & 27.7 \\
\hline Tertiary education & 98 & 17.7 \\
\hline \multicolumn{3}{|l|}{ Sentence length (years) } \\
\hline$<2$ & 265 & 48.0 \\
\hline $2-9.9$ & 106 & 19.2 \\
\hline$\geq 10$ & 181 & 32.8 \\
\hline \multicolumn{3}{|c|}{ Length of stay in the correctional institution (years) } \\
\hline$<2$ & 258 & 46.7 \\
\hline $2-4.9$ & 152 & 27.5 \\
\hline$\geq 5$ & 142 & 25.7 \\
\hline \multicolumn{3}{|c|}{ Work in the correctional institution } \\
\hline Yes & 276 & 50.0 \\
\hline No & 276 & 50.0 \\
\hline
\end{tabular}

Abbreviation: BMI, body mass index.

previously diagnosed with COPD, 53.3\% (8/15) had been diagnosed at least 10 years before enrolment. According to the GOLD 2009 guidelines, the majority of participants $(51.5 \%)$ were stage II, followed by $36.4 \%$ in GOLD stage I (Table 2).

COPD prevalence significantly differed among the detention premises of the study $(P<0.001)$, with the highest prevalence reported for the detention premise of Patras (25.9\%; 95\% CI: 15.3-39.0), followed by the detention premise of Volos (20.0\%; 95\% CI: 4.3-48.1), while no cases of COPD were identified in the sites of Halkida and Amfissa (Figure 1A). In addition, the prevalence of COPD increased with age $(P<0.001)$ (Figure 1B), being $1.85 \%$ 
Table 2 COPD characteristics and vital signs

\begin{tabular}{|c|c|c|}
\hline $\mathrm{N}=\mathbf{5 5 2}$ & Median & Interquartile range \\
\hline FEV, prebronchodilation (\%) & 96.0 & $85.0-106.0$ \\
\hline FEV, postbronchodilation (\%) & 98.5 & $88.0-109.0$ \\
\hline \multicolumn{3}{|l|}{$(\mathrm{mmHg})$} \\
\hline \multicolumn{3}{|l|}{$(\mathrm{mmHg})$} \\
\hline Heart rate $(\mathrm{bpm})$ & 78.0 & $70.0-85.0$ \\
\hline \multirow[t]{2}{*}{ Oxygen saturation (\%) } & 98.0 & $97.0-98.0$ \\
\hline & $\mathbf{n}$ & $\%$ \\
\hline COPD diagnosis & 33 & 6.0 \\
\hline Newly diagnosed & 18 & 3.3 \\
\hline Previously diagnosed & 15 & 2.7 \\
\hline \multicolumn{3}{|l|}{ Years since diagnosis $(n=15)$} \\
\hline 1 & 1 & 6.7 \\
\hline 2 & 3 & 20.0 \\
\hline 4 & 1 & 13.3 \\
\hline 7 & 2 & 13.3 \\
\hline 10 & 2 & 6.7 \\
\hline 12 & 1 & 6.7 \\
\hline 20 & I & 6.7 \\
\hline 25 & 1 & 6.7 \\
\hline 30 & 2 & 13.3 \\
\hline 40 & I & 6.7 \\
\hline \multicolumn{3}{|c|}{ COPD stage (GOLD 2009 criteria) $(n=33)$} \\
\hline I & 12 & 36.4 \\
\hline II & 17 & 51.5 \\
\hline III & 4 & 12.1 \\
\hline Chronic bronchitis & 24 & 4.3 \\
\hline Pulmonary emphysema & 3 & 0.5 \\
\hline \multicolumn{3}{|c|}{ Number of exacerbations in the previous year $(n=15)$} \\
\hline 1 & I & 2.2 \\
\hline 2 & 3 & 6.7 \\
\hline 3 & 4 & 8.9 \\
\hline 4 & I & 2.2 \\
\hline$\geq 5$ & 6 & 13.3 \\
\hline \multicolumn{3}{|c|}{ Hospitalizations due to COPD ( $n=7)$} \\
\hline 1 & 3 & 7.5 \\
\hline 2 & I & 2.5 \\
\hline 3 & 1 & 2.5 \\
\hline 5 & 1 & 2.5 \\
\hline 6 & I & 2.5 \\
\hline
\end{tabular}

Abbreviations: $\mathrm{FEV}_{1}$, forced expiratory volume in I second; GOLD, Global initiative for chronic Obstructive Lung Disease.

(95\% CI: 0.51-4.67) among those aged 30-39.9 years, $2.56 \%$ (95\% CI: 0.70-6.44) among those aged 40-49.9 years, but $11.57 \%$ (95\% CI: $6.47-18.65$ ) and $18.64 \%$ (95\% CI: 9.69 30.92 ) among those aged $50-59.9$ years and $\geq 60$ years, respectively. Moreover, prevalence was higher among those living in correctional institutions for $>5$ years $(12.7 \%$; $95 \%$ CI: 7.7-19.3) compared to those whose length of stay was $2-4.9$ years $(2.0 ; 95 \%$ CI: $0.4-5.7)$ or $<2$ years $(4.6 \%$; $95 \%$ CI: 2.4-8.0) (Figure 1C) $(P<0.001)$; prevalence was also higher in participants whose sentence length was longer (Figure 1D) $(P<0.001)$.

In this study, COPD staging was done according to the GOLD 2009 guidelines, and the majority of patients (51.5\%) were staged as GOLD I, followed by $36.4 \%$ in GOLD stage II.

It seems that COPD staging results in prisons are similar to those to the free society, where the majority of COPD patients are of stages I and II, and they are often undiagnosed because of the underestimation of the implications of smoking habit and of chronic bronchitis daily symptoms.

The most commonly reported symptoms among prisoners were cough (29.5\%) and dyspnea (25.7\%), and according to the medical research council (MRC) scale, the majority of participants were either at MRC stage 0 or at MRC stage 1 (47.1\% and $41.2 \%$, respectively).

Other reported morbidities in prisoners' population included primarily drug use (33.3\%) and alcohol consumption (26.6\%). Arterial hypertension, hyperlipidemia, diabetes mellitus, and depression are the most common health problems among study participants $(14.1 \%, 9.4 \%, 8.2 \%$, and $6.5 \%$, respectively) as it is in free society.

Stress levels and health-related quality of life were measured with PSS and EQ-5D, respectively. The median obtained in PSS reached 25, which is much higher than average, indicating that the stress inmates are experiencing in the daily lives.

Out of the five areas of focus in the EQ-5D, the one focusing on anxiety/depression illustrated $46.1 \%$ moderate and $36.1 \%$ high levels, which is in agreement with the results obtained from the PSS.

A total of 15 participants (45.4\%) among the COPD population reported at least one exacerbation in the past year, while seven reported being hospitalized (Table 2). The most commonly reported respiratory symptoms were cough $(29.5 \% ; 163 / 552)$, dyspnea $(25.7 \% ; 142 / 552)$, and sputum $(22.6 \% ; 125 / 552)$. Among those with confirmed COPD, dyspnea severity was assessed according to the MRC scale ( $n=102), 47.1 \%$ and $41.2 \%$ had MRC grades 0 and 1 , respectively.

\section{COPD treatment}

A total of 16 participants, corresponding to $48.5 \%$ of the COPD population, were receiving treatment for COPD. Among these participants, the main COPD treatments included inhaled corticosteroids (ICS) (56.2\%), fixed-dose combinations of long-acting beta antagonist (LABA) + ICS (37.5\%), LABA (18.8\%), and long-acting muscarinic antagonists (18.8\%). 


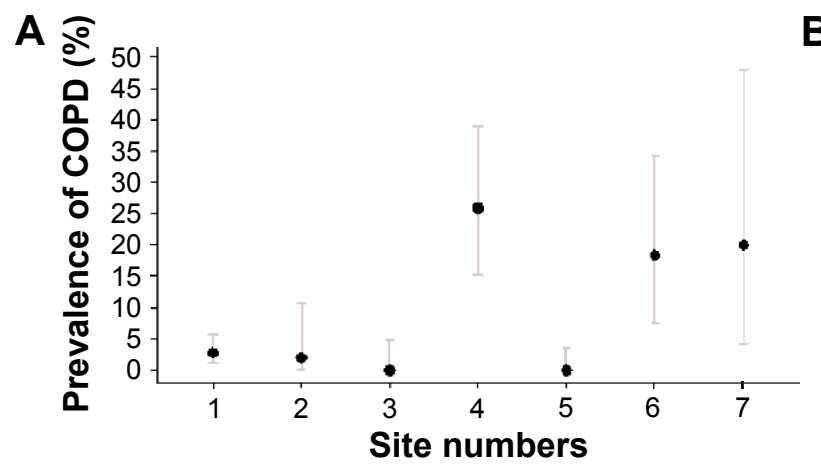

$P$-value (exact test): $<0.001$

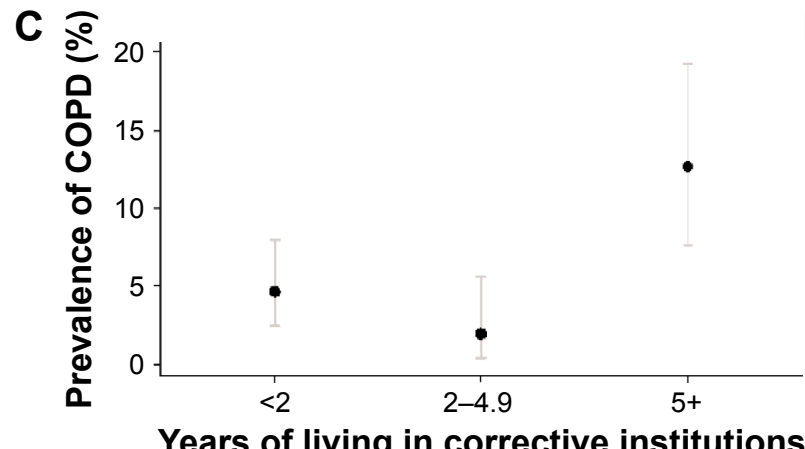

$P$-value (exact test): $<0.001$
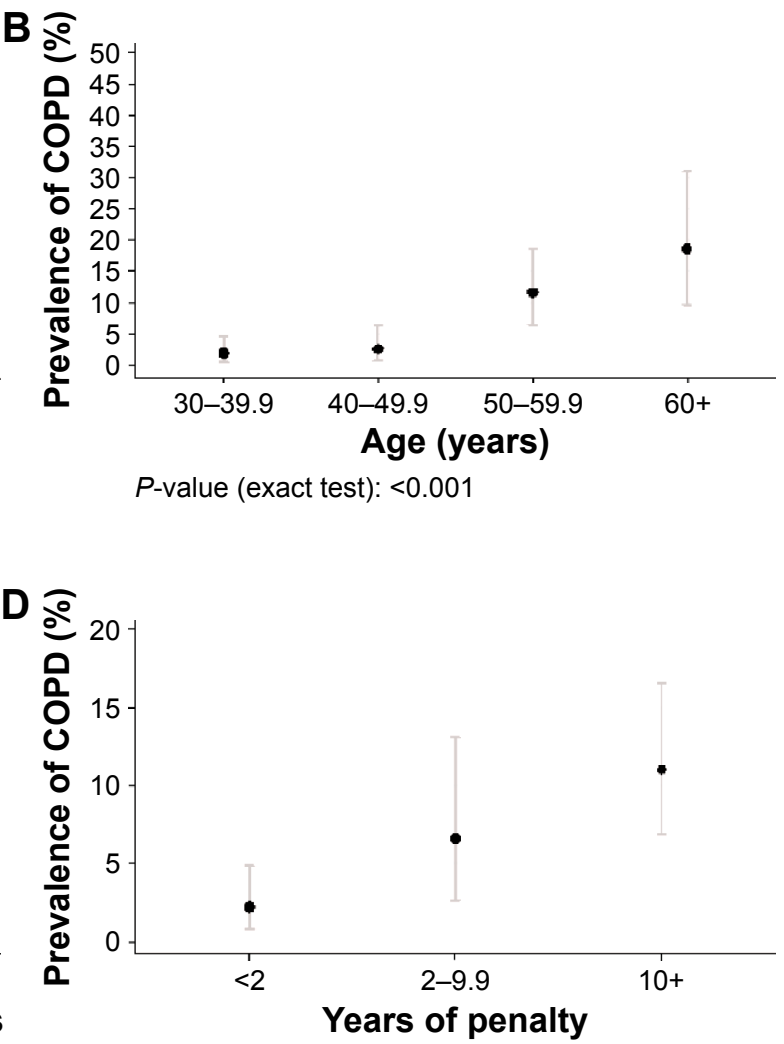

$P$-value (exact test): $<0.001$

- Prevalence (\%) $\quad 95 \% \mathrm{Cl}$

Figure I Prevalence of COPD and patient characteristics.

Notes: (A) Prevalence of COPD in each detention premise. I: male section of Korydallos, Athens ( $n=250)$, 2: female section of Korydallos, Athens ( $n=50$ ), 3: detention premise of Halkida ( $n=60)$, 4: detention premise of Patra $(n=58)$, 5: detention premise of Amfissa $(n=81), 6$ : detention premise of Larisa $(n=38)$, and 7: detention premise of Volos $(n=15)$. (B) Prevalence of COPD according to age (years). The distribution of the participants per age group was as follows: 30-39.9 years ( $n=216$ ), 40-49.9 years $(n=156), 50-59.9$ years $(n=121)$, and $\geq 60$ years $(n=59)$. (C) Prevalence of COPD according to the length of stay in the detention premise. The distribution of the participants per length of stay in the detention premise was as follows: $<2$ years $(n=258), 2-4.9$ years $(n=152)$, and $\geq 5$ years ( $n=142)$. (D) Prevalence of COPD according to sentence length. The distribution of the participants per sentence length was as follows: $<2$ years $(n=265), 2-9.9$ years $(n=106)$, and $\geq 10$ years $(n=18 I)$.

Abbreviation: $\mathrm{Cl}$, confidence interval.

\section{Comorbidities: alcohol and substance use}

Comorbid conditions including alcohol and substance use disorders were present in $68.1 \%$ of the participants, with illicit drug use (33.3\%), alcohol consumption (26.6\%), arterial hypertension (14.1\%), hyperlipidemia (9.4\%), hepatitis C (8.7\%), diabetes mellitus (8.2\%), and depression (6.5\%), being among the most prevalent.

\section{Stress levels and HRQoL}

Stress levels were assessed with the PSS-14. In the present study, the median PSS-14 score was 25.0 (IQR: 17.0-32.0) in the overall population and did not significantly differ between participants with and without COPD (22.5 [IQR: 15.5-31.5] versus 26 [IQR: $18-32$ ]; $P=0.198$ ).

HRQoL was assessed with the EQ-5D-3L questionnaire. The median EQ-VAS (EuroQol visual analog scale) score was 70.0 (IQR: 60.0-90.0). The EQ-VAS was similar between participants with COPD (70 [IQR: 50-80]) and without COPD (70 [IQR: 60-90]) $(P=0.094)$. The median EQ-5D index score was 0.8 (IQR: $0.5-0.8$ ). The proportions of participants with "problems" in each of the EQ-5D dimensions were $2.0 \%$ for the self-care dimension, $4.5 \%$ for the usual activities, $6.2 \%$ for the dimension of mobility, $20.7 \%$ for the pain/discomfort, and $82.8 \%$ for the dimension of anxiety/depression, as graphically presented in Figure 2 .

\section{Discussion}

The data obtained from our study demonstrate that the prevalence of COPD in Greek correctional institutions is lower than the estimated general population prevalence in those aged $>35$ years in one study ${ }^{4}$ but similar to the rate observed among a sample of the general population aged $21-80$ years 


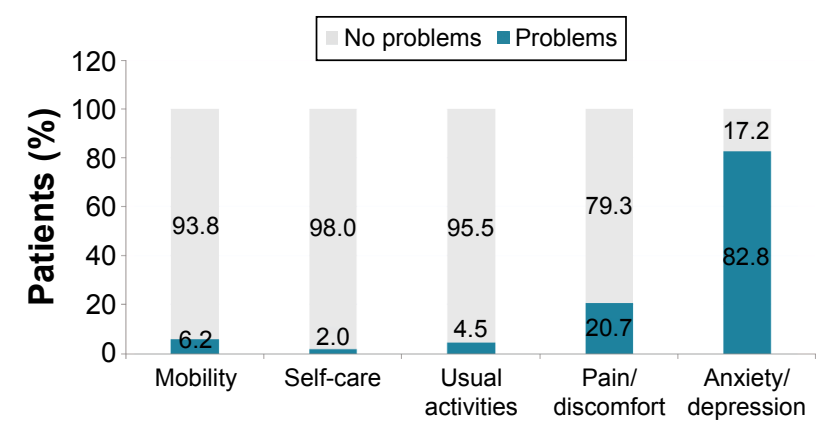

Figure 2 Participants with problems/no problems in each of the EQ-5D ( $N=552)$. Abbreviation: EQ-5D, EuroQoL Group's five dimension.

residing in Northern Greece..$^{22}$ The COPD prevalence herein is larger than that in a study conducted in the US: Texas prison system, where the overall crude prevalence of COPD was higher (1.8\%) among non-Hispanic white inmates ${ }^{19}$ as well as that in a study conducted in Spanish prisons. ${ }^{15}$

Importantly, the present study adds to the evidence that prevalence of COPD increases with age, since the estimated prevalence of COPD varied among the age groups, being the highest among those aged $\geq 60$ years compared to those aged 40-49.9 years. Similarly, the study of Harzke et al has reported a prevalence of $11.4 \%$ among non-Hispanic white inmates aged $\geq 55$ years versus $3.2 \%$ among those aged $45-54$ years. ${ }^{19}$ It thus appears that the low median age of the study population herein (43.0 years) has likely contributed to the relatively low prevalence of COPD observed. It is worthy to mention that 2012 data from the Korydallos detention premise indicate a median age of 30 years, with $7.2 \%$ being $\geq 50$ years of age, compared to $32.6 \%$ in our study, suggesting that there is a trend toward an aging of the prison population ${ }^{23}$ which will likely increase the prevalence of COPD.

Importantly, the observed prevalence of current smokers was high, in agreement with the previous studies, ${ }^{9,10}$ assessed as having a strong dependence to nicotine. The high proportion of smokers may be influenced by the high proportion of patients with problems in the anxiety/depression dimension of the EQ-5D, a common finding among inmates. ${ }^{24}$ In addition, the overall HRQoL of the participants was diminished as indicated by the median EQ-VAS of 70, lower than the median of 80 reported for the general population. ${ }^{22}$

Regarding the severity of COPD among those inmates who were diagnosed with COPD, most appeared to have mild or moderate disease severity, in accordance with percentage observed in studies of the general population of Greece., ${ }^{4,25}$ Nearly half were receiving treatment for COPD, mainly based on the use of ICS (either alone or in fixed-dose combination with LABAs). In addition, a total of $31 \%(14 / 45)$ of the participants self-reported $\geq 2$ exacerbations in the last year, which is according to the GOLD 2013 combined assessment approach criteria that would classify them in the high-risk categories ( $\mathrm{C}$ and $\mathrm{D})$, despite the fact that they may have been diagnosed with mild-to-moderate COPD (stage I or II). Overall, the findings regarding the hospitalizations and exacerbation history imply that the burden of the disease within the correctional system is high.

There are certain limitations to the study that should be considered when interpreting the outcomes. In accordance with its cross-sectional, epidemiological design, GNOSIS bears the limitations attributed to studies of such design, including missing data. Apart from the MRC dyspnea scale, which was not completed by all study participants, no other data were considered missing. Notably, the outcomes of the MRC dyspnea scale do not influence the interpretation of the main study objectives, as COPD diagnosis was based on the spirometry testing which was performed for all participants.

An additional limitation may stem from the fact that inmates may be hesitant to provide a full report of symptoms or prior diagnoses, which combined with the fact that inmates are often from low socioeconomic backgrounds with reduced access to (or desire to access) health care systems, results in underestimation of the participants' comorbidity burden and self-reported COPD symptoms and characteristics. Importantly, COPD prevalence represents an objective finding since it was estimated based on the spirometry testing performed during the course of the study. Information bias may also have been introduced in all data obtained through recall/response. In addition, the data may be amenable to imprecision in the responses: selective memory (remembering or not remembering experiences or events that occurred at some point in the past) as well as telescoping (eg, assigning events that have occurred at one time to another time). ${ }^{26}$

With regards to the PROs employed in the present study, they all comprise extensively used standardized and validated instruments, with the Greek validated and standardized versions of EQ-5D-3L and PSS-14 used herein. ${ }^{22-24}$ However, since these instruments were completed during the interview of the physician with the participant, interviewing bias might have occurred. In addition, bias due to the desire of the participants to be portrayed favorably or exaggeration of their symptoms and severity, ${ }^{27}$ as well as recall bias in the PSS-14 questionnaire, which employs a month recall period, may all have limited the robustness of the findings from the PROs. Moreover, bias may have been introduced due to the fact that $20.8 \%$ of the population was nonnative speakers 
of Greek but was asked to answer the questionnaires in the Greek language. On the other hand, the results obtained depict real-life conditions, and thus are more representative of both the population of interest and the clinical outcomes under observation. Regarding the generalizability of the outcomes, it is noted that the study was conducted among detention premises throughout Greece and is representative of the imprisoned population, albeit more so of the male population.

\section{Conclusion}

Our study findings indicate an overall prevalence of smoking of $79 \%$ and prevalence of COPD of $6 \%$ in the inmates of correctional institutions in Greece, with $18.6 \%$ among those aged $\geq 60$ years and $11.6 \%$ among those aged $50-59.9$ years, providing data about a potential increase in the prevalence of COPD in the years to come due to the aging of the prison population. The prevalence of smoking combined with the observed increase in the prevalence of COPD with the length of stay in the detention premises and the sentence length might also lead to an increase in the prevalence of COPD in the years ahead.

Along with the high proportion of those who smoked increasingly since imprisonment, these findings advocate the need for implementation of measures to decrease smoking among the population of the correctional institutions.

The results of GNOSIS have provided a snapshot of the prevalence of COPD, smoking, and other COPD risk factors in the setting of the Greek correctional institutions. Further studies are warranted to establish the link between potential COPD risk factors suggested herein and disease prevalence. The findings support the trend that prevalence of COPD in detention premises of Greece is likely to rise in the years ahead unless immediate actions are taken to improve health conditions, to increase smoking cessation, and to reduce overcrowding.

\section{Acknowledgments}

The authors would like to thank the medical doctors Konstantinos Galanis, Nikolaos Palaiologos, Evangelos Thanasas, Stergios Antoniou, Eugenia Tsoukala, Dimitris Adamopoulos, Dionysia Michalakopoulou, and Efstratios Spiliotis and all the health personnel of the corrective institutions for their contribution to the study. The study was funded by Novartis Hellas.

\section{Author contributions}

Eleni G Bania and Konstantinos I Gourgoulianis were involved in the study conception and design. Eleni $\mathrm{G}$ Bania and Eirini Mitsiki collected the data. Evangelos C
Alexopoulos performed the statistical analysis of the data. Eleni G Bania, Konstantinos I Gourgoulianis, Evangelos C Alexopoulos, and Eirini Mitsiki prepared the manuscript. Zoe Daniil and Chrysa Hatzoglou participated in the study design and reviewed and commented the abstract. Konstantinos I Gourgoulianis was the scientist responsible for this study. All authors contributed toward data analysis, drafting and critically revising the paper and agree to be accountable for all aspects of the work.

\section{Disclosure}

Eleni G Bania has worked for Novartis during the time of study conception and execution. Evangelos C Alexopoulos held a contract with Novartis for participating in the study design and performing the statistical analysis. Eirini Mitsiki is currently working for Novartis. The authors report no further conflicts of interest in this work.

\section{References}

1. World Health Organisation. Burden of COPD. 2014. Available from: http://www.who.int/respiratory/copd/burden/en/index.html. Accessed December 22, 2014.

2. World Health Organisation. The Top 10 Causes of Death. Fact Sheet $N^{\circ} 310$. 2014. [updated May, 2014]. Available from: http://who.int/ mediacentre/factsheets/fs310/en/. Accessed December 22, 2014.

3. Vestbo J, Hurd SS, Agustí AG, et al. Global strategy for the diagnosis, management, and prevention of chronic obstructive pulmonary disease: GOLD executive summary. Am J Respir Crit Care Med. 2013; 187(4):347-365.

4. Tzanakis N, Anagnostopoulou U, Filaditaki V, Christaki P, Siafakas N. COPD group of the Hellenic Thoracic Society. Prevalence of COPD in Greece. Chest. 2004;125(3):892-900.

5. Minas M, Hatzoglou C, Karetsi E, et al. COPD prevalence and the differences between newly and previously diagnosed COPD patients in a spirometry program. Prim Care Respir J. 2010;19(4):363-370.

6. Konstantikaki V, Kostikas K, Minas M, et al. Comparison of a network of primary care physicians and an open spirometry programme for COPD diagnosis. Respir Med. 2011;105(2):274-281.

7. Harvard School of Public Health. The Greek Tobacco Epidemic. Boston: Center for Global Tobacco Control; 2011. Available from: www.smokefreegreece.org. Accessed December 22, 2014.

8. Filippidis FT, Vardavas CI, Loukopoulou A, Behrakis P, Connolly GN, Tountas Y. Prevalence and determinants of tobacco use among adults in Greece: 4 year trends. Eur J Public Health. 2013;23(5):772-776.

9. Papadodima SA, Sakelliadis EI, Sergentanis TN, Giotakos O, Sergentanis IN, Spiliopoulou CA. Smoking in prison: a hierarchical approach at the crossroad of personality and childhood events. Eur J Public Health. 2010;20(4):470-474.

10. Makris E, Gourgoulianis KI, Hatzoglou C. Prisoners and cigarettes or 'imprisoned in cigarettes'? What helps prisoners quit smoking? BMC Public Health. 2012;12:508.

11. Greek Ministry of Justice. Statistical Figures Pertaining to Imprisoned People-Sentences. 2014. Available at http://www.ministryofjustice.gr/ site/el/APXIKH.aspx. Accessed December 17, 2014.

12. Maculan A, Ronco D, Vianello F. Prison in Europe: Overview and Trends. European Prison Observatory. Detention Conditions in the European Union. Antigone Edizioni, Rome: 2013. [ISBN: 978-8898688-08-1].

13. Malliori M, Sypsa V, Psichogiou M, et al. A survey of bloodborne viruses and associated risk behaviours in Greek prisons. Addiction. 1998;93(2):243-251. 
14. Anastassopoulou CG, Paraskevis D, Sypsa V, et al. Prevalence patterns and genotypes of $\mathrm{GB}$ virus $\mathrm{C} /$ hepatitis $\mathrm{G}$ virus among imprisoned intravenous drug users. J Med Virol. 1998;56(3):246-252.

15. Vera-Remartínez EJ, Borraz-Fernández JR, Domínguez-Zamorano JA, et al; GESESP (Grupo de Enfermería Sociedad Española de Sanidad Penitenciaria). Prevalence of chronic diseases and risk factors among the Spanish prison population. Rev Esp Sanid Penit. 2014;16(2):38-47.

16. Wilper AP, Woolhandler S, Boyd JW, et al. The health and health care of US prisoners: results of a nationwide survey. Am J Public Health. 2009; 99:666-671.

17. Binswanger IA, Krueger PM, Steiner JF. Prevalence of chronic medical conditions among jail and prison inmates in the USA compared with the general population. J Epidemiol Community Health. 2009; 63:912-919.

18. Baillargeon J, Black SA, Pulvino J, Dunn K. The disease profile of Texas prison inmates. Ann Epidemiol. 2000;10:74-80.

19. Harzke AJ, Baillargeon JG, Pruitt SL, Pulvino JS, Paar DP, Kelley MF. Prevalence of chronic medical conditions among inmates in the Texas prison system. J Urban Health. 2010;87(3):486-503.

20. Heatherton TF, Kozlowski LT, Frecker RC, Fagerström KO. The Fagerström test for nicotine dependence: a revision of the Fagerström tolerance questionnaire. Br J Addict. 1991;86(9):1119-1127.
21. Cohen S, Kamarck T, Mermelstein R. A global measure of perceived stress. J Health Soc Behav. 1983;24(4):385-396.

22. Andreou E, Alexopoulos EC, Lionis C, et al. Perceived stress scale: reliability and validity study in Greece. Int J Environ Res Public Health. 2011;8:3287-3298.

23. Rabin R, de Charro F. EQ-5D: a measure of health status from the EuroQol Group. Ann Med. 2001;33:337-343.

24. Yfantopoulos J. The Greek version of EuroQol (EQ-5D) instrument. Arch Hellenic Med. 2001;18:180-191.

25. Alexopoulos EC, Palatsidi V, Tigani X, Darviri C. Exploring stress levels, job satisfaction, and quality of life in a sample of police officers in Greece. Saf Health Work. 2014;5(4):210-215.

26. Alexopoulos EC, Geitona, M. Self-rated health: Inequalities and potential determinants. Int J Environ Res Public Health. 2009;6: 2456-2469.

27. Togas C, Raikou M, Niakas D. An assessment of health related quality of life in a male prison population in Greece associations with health related characteristics and characteristics of detention. Biomed Res Int 2014;2014:274804.
International Journal of COPD

\section{Publish your work in this journal}

The International Journal of COPD is an international, peer-reviewed journal of therapeutics and pharmacology focusing on concise rapid reporting of clinical studies and reviews in COPD. Special focus is given to the pathophysiological processes underlying the disease, intervention programs, patient focused education, and self management protocols.

\section{Dovepress}

This journal is indexed on PubMed Central, MedLine and CAS. The manuscript management system is completely online and includes a very quick and fair peer-review system, which is all easy to use. Visit http://www.dovepress.com/testimonials.php to read real quotes from published authors.

Submit your manuscript here: http://www.dovepress.com/international-journal-of-chronic-obstructive-pulmonary-disease-journal 